\title{
The User Reconfigured: On Subjectivities of Information
}

\author{
Jeffrey Bardzell \\ Informatics and Computing \\ Indiana University \\ Bloomington, IN 47408 \\ jbardzel@indiana.edu
}

\author{
Shaowen Bardzell \\ Informatics and Computing \\ Indiana University \\ Bloomington, IN 47408 \\ selu@indiana.edu
}

\begin{abstract}
Foundational to HCI is the notion of "the user." Whether a cognitive processor, social actor, consumer, or even a nonuser, the user in HCI has always been as much a technical construct as actual people using systems. We explore an emerging formulation of the user-the subjectivity of information - by laying out what it means and why researchers are being drawn to it. We then use it to guide a case study of a relatively marginal use of computing - digitally mediated sexuality - to holistically explore design in relation to embodiment, tactual experience, sociability, power, ideology, selfhood, and activism. We argue that subjectivities of information clarifies the relationships between design choices and embodied experiences, ways that designers design users and not just products, and ways to cultivate and transform, rather than merely support, human agency.
\end{abstract}

\section{Author Keywords}

User; subjectivity; sexuality; theory; criticism

\section{ACM Classification Keywords \\ H5.m. Information systems: Miscellaneous.}

\section{INTRODUCTION}

A decennial conference beckons us to reflect with a wider perspective than our everyday research often affords. We reflect in this paper on the ways that HCI has theorized the user. We begin in the early 1980s, when notions of "usability" and "user-centered design" were first consolidating a notion of the user-one that would quickly be criticized and reworked, beginning an ongoing activity that continues today. We will turn our attention to an emerging formulation in HCI of the user that is informed by recent philosophy: the user as a subjectivity of information. After characterizing what this formulation means, we then seek to test it. We do so by investigating a marginal use of computing, digitally mediated sexuality. We choose this use because it brings onto the same stage a diverse range of concerns that HCI is increasingly seeking to take on: design, embodiment, tactual experience, sociability, power, ideology, selfhood, and activism. Sexuality has also centrally figured in

Copyright $($ C 2015 is held by the author(s). Publication rights licensed to Aarhus University and ACM

5th Decennial Aarhus Conference on Critical Alternatives

August 17 - 21, 2015, Aarhus Denmark

DOI: http://dx.doi.org/10.7146/aahcc.v1i1.21298 theorizing subjectivity in the humanities. Using critical and empirical methods, we explore sexual subjectivity as designed, and reflect back on the benefits and limits of subjectivities of information as a formulation of computing use.

\section{USER AND SUBJECT}

Although at first blush "the user" might seem to be very obvious in its meaning - it's the person who is using a system! - in fact HCI researchers and practitioners operate with evolving understandings that have been informed for years by technical understandings, grounded in epistemological, ethical, and methodological commitments. Even the following brief survey makes this clear. In their 1983 classic, Card, Moran, and Newell [8] characterize the user thus:

a scientific psychology should help us in arranging this interface so it is easy, efficient, error-free-even enjoyable.... The key notion is that the user and the computer engage in a communicative dialogue whose purpose is the accomplishment of some task.... The human mind is also an information processing system. (pp.1, 4, 24)

In 1985 Gould and Lewis [16] proposed a three-part methodology for systems design: an early focus on users, empirical measurements, and iterative design. And in 1988, Norman [26] advised, "make sure that (1) the user can figure out what to do, and (2) the user can tell what is going on" (p.188). Common to these is the user understood as an individual completing a task with a system, where the human is abstracted as a cognitive processor well defined needs; tasks are understood as behavioral sequences that can be explicitly defined; and interaction is understood as a dialogue between this cognitive processer and the task needing to be done-and all of the above were available to and measurable by empirical methods.

But it was not long before these formulations were critiqued and expanded. In 1986 and 1987, respectively, Winograd and Flores [46] and Suchman [40] challenged the view of the human constructed by these earlier notions of the user, leveraging philosophy to rethink what it means to act in a situation. Bannon \& Bødker [1] wrote that in classic HCI, the user had been "hacked into" a "disembodied ratiocinator," referring to cognitive modeling disengaged from social and material praxis. Kuutti [22] and Cockton [10] would later trace three HCI "users" emerging in the research discourse from the 1980 s to the 2000s: the user as source of error, as social actor, and as consumer, broadly corresponding to changes in computing paradigms over the decades, 
from one-user-one-terminal systems, towards systems supporting workplace cooperation, and finally towards experience-oriented systems. More recent work has added the "non-user" to the mix as well [31].

More radically, Cooper \& Bowers [11] analyzed "the user" as a discursive structure, rather than an actual person:

The representation of the user [in HCI discourses] can be analytically broken down into three constituent and mutually dependent moments [as follows...] In the first, the user is created as a new discursive object that is to be HCI's concern [...] In the second, HCI tends to construct cognitive representations of the user [...] In the third, HCI represents the user in the political sense of 'representation': as Landauer puts it, people within HCI should be the 'advocates of the interests of users'. [p.50]

The present work continues this thinking, analyzing the user in relation to abstract structural positions or roles that are inhabited by actual people using systems in real situations.

\section{Situated Actors and/or Structured Roles}

The key conceptual move is to distinguish the user qua an individual person-an embodied actor in a given situation-from the user qua structural roles, with anticipated needs and capabilities. We make this move because the former - the user qua embodied individual-maps (perhaps too intuitively) onto everyday notions of persons as already given: that is, that the individual is already there, and our job as designers is to support that individual in achieving a need. What the latter-the user qua structural role-gives us is not only a type of individual whom we can support, but also an analytic means to think about designing the role itself, i.e., designing not just the system but also the user. (We believe that designers already design both systems and users, but some HCI theory, fusing with ordinary language notions of personhood, obfuscates that we also design the user-consider, again, how most will parse Norman's dictum: "make sure that the user can figure out what to do....")

Our argument is that to resist the analytical conflation of situated actors and discursive constructs into "the user," that we should analyze "the user" as a "subjectivity of information," that is, structural roles that are designable and designed, which users-as-situated-actors take up and perform. In what follows, we will argue that such a view has practical advantages for HCI researchers and designers, as well as important methodological implications.

\section{Subjectivities of Information}

The concept of subjectivity is derived from the philosophy of Lacan, Althusser, Foucault, Delueze \& Guattari, Butler, and others. Two related concepts are at the core of this theory: the notion of subject positions, which are social roles that people are thrust into, and subjectivity, which is the felt experience and creative agency of individuals within that situation. Subject positions are typically relational, that is, requiring another: teacher-student, mother-daughter, policecitizen, designer-user. Subjectivities are more diverse and situated: two students can occupy the same subject position and yet perform distinctly different behaviors and attitudes. A subject position thus constrains possible behaviors, attitudes, etc., but it also provides generative "rules" for creative, stylized, and individual performances within them. Any individual occupies many different subject positions: a schoolchild is also a daughter, a citizen, a goalie, etc. Subject positions can come into conflict, thus shaping (and helping explain) how an individual negotiates them.

We can apply this concept to computer use. Common IT subject positions include power users, novices, early adopters, and non-users; social actors; gamers, trolls, and n00bs; standard users and admins; expert amateurs and everyday designers; quantified selves; makers and hackers; social media friends; and many more. It is clear that all of these positions comprise both technical and social roles. The concept of subjectivities gets at how these roles are diversely enacted, embodied, or performed. For example, we understand how step- and calorie-counting apps construct quantified self subject positions, but how those apps are subjectively experienced (e.g., as a source of empowerment, anxiety, and/or curiosity) and how they are enacted or stylized (e.g., integrated into one's lifestyle, displayed and/or hidden from the view of others) is a different type of question. Subject positions are analytically available to research, while subjectivities are empirically available.

We understand subjectivity of information to refer to any combination of (structural) subject positions and (felt and performed) subjectivities relevant to the context of information technology use. We do not mean to reify a subjectivity of information as somehow distinct or independent from other subjectivities. We simply understand the concept in its usual theoretical sense, applied in the domain of IT design and use. That is, we seek to understand "users" insofar as they are structurally subjected to certain IT systems and associated social practices, and how they become subjects of (i.e., agents of) those systems and social practices. These are analytically distinct from "users" as commonsense persons because a given person can inhabit multiple subject positions and can experience/perform them not only differently from other individuals, but even differently from themselves at different times or in different situations.

We argue that the notion of subjectivities of information has three benefits. It can give us a tighter analytic coupling between specific design decisions and particular social experiences, because the design decisions and social experiences can both be analyzed using an analytic vocabulary common to both, i.e., the structures that comprise that subject position, understood as an amalgam of computational rules and social structures, including rights and responsibilities, laws, mores, etc. Second, it makes clear that we can (and do) design subjects as well as interfaces, products, and services (while recalling that the parallel concept of subjec- 
tivities means that individuals have plenty of agency beyond what we can prescribe as subject positions). And finally, such a view supports design practices aimed at cultivating and transforming, rather than merely supporting or extending, human agency; one use of subjectivity in critical theory has been to serve activist purposes, to imagine and pursue the transformation of society.

\section{Methodologies for Information Subjectivities}

The user as subjectivity of information has methodological implications, because "the subject" is shaped by sociotechnical structures that include individual algorithms and system structures (e.g., permissions, task sequences), and also social structures, including shared practices, intersubjective understandings, policies, and broader sociological structures including gender, racial, and class ideologies. As such, the subject is not a simple given, and cannot be rendered available to understanding merely with data, but rather it must be interpreted, a critical activity that makes sense of multiple sources, including systems, empirical studies of users, and analysis of data-all of which can be supported by relevant theories. One methodological challenge, then, becomes how we weigh differing theoretical, data, and critique-based resources in interpreting the subject.

Adapting from feminist film theory [43], we can distinguish three sources of the subject: cultural objects (i.e., interactive technologies for our purposes) that express expectations about their ideal user who will get the most out of them; actual users, who have their own experiences, purposes, and perspectives about their use of an object; and researchers/critics, who offer a trained expert perspective on objects. Most research only accesses one or two of these positions. For example, if a work of interaction criticism $[2,5]$ asserts that a system manipulates users, two of the three positions are active-the critic and the inscribed user-but not the second (actual users). When HCI researchers study the actual aesthetic judgments that users make (e.g., [41]), they are activating the second but not the first and third positions.

Once we acknowledge these three positions, another research challenge comes into focus: they often do not agree. The "actual" meaning of the design, then, must be some negotiation of these different positions. A methodological strategy proposed by feminist researchers to study subjectivity has been to deploy a critical-empirical approach. For example, in a landmark study of romance novels, feminist literary critic Janice Radway [29] read the romance novel genre as patriarchal (because it offers narratives that reassure and satisfy women while preserving an unequal status quo), and then she ethnographically studied working class women readers. Not surprisingly, their literary understandings did not agree. The dilemma for Radway, then, is this: as a scholar trained in feminist theory, Radway is in a position to see "false pleasures" that everyday readers may not be able or want to see; one cannot dismiss Radway's reading simply because the everyday readers did not see things the way she did. But as a feminist, Radway must acknowledge and contend with the value that actual women find in these texts.

Radway's dilemma is HCI's as well: if researchers cede the authority of identifying the sociotechnical significances of systems to actual users, we risk overlooking to the very subtle roles of ideology and false pleasure in systems, an approach that is ultimately regressive. If HCI researchers instead become more active critics, we risk speaking for users, substituting our own values for theirs. Thus we believe something akin to the methodology that Radway sought to undertake, which stages a dialogue between equally weighted critical and empirical studies of the same phenomenon, might be an appropriate strategy for investigating the meanings of interactive products - and the subject positions and subjectivities inscribed within them.

\section{A CRITICAL-EMPIRICAL STUDY OF SOCIOTECHNICAL SEXUAL SUBJECTS}

The shift to envisioning users as sociotechnical subjects is anything but new: it is the outcome of a generation of research and theory throughout HCI, explored in CSCW, participatory design, in traditional user research, and so on (see e.g., [12]; the term "subjectivities of information" itself was coined by Paul Dourish). Because we see analysis of sociotechnical subjects as involving (at least) three planes of meaning (i.e., the values and subject positions inscribed in designs; the skilled practices of actual users; and the critique of domain experts), we undertook a research initiative that engages all three.

The research focuses on a paradigmatic change that began about a decade ago in sex toy design. Prior to it, sex toy design was linked to the porn industry, marketed to men, manufactured cheaply, and called "novelty products" to avoid regulation under medical standards. Since then, the industry has been transformed by designers with backgrounds in high-end industrial design, including Apple, Ericsson, Frog Design, and so on; the toys are manufactured according to the standards of modern consumer electronics (e.g., MP3 players) and in most cases using medical grade, body-safe materials; they are marketed to women as luxury accessories; their price point is generally higher and in some cases much higher; and they align themselves with feminist sex positive activists who seek to transform the meanings and consequences of sexual body practices (see [3]). Broader cultural meanings of sex toys also changed in this time, with episodes of television shows, such as Sex \& the City, presenting them in a positive light.

Our overall research program on sex and HCI has included an interview study with sex toy designers and feminist sex activists, critical analysis of sex toys, and empirical studies of digitally mediated sexual life in virtual worlds, on social media, and with digital sex toys. Some of this research has been reported elsewhere [3], so we focus here on a criticalempirical study of sex toys and their sexual subjectivities. 
In conducting this research, we are able to focus on the interrelations of critical and empirical epistemologies for design and user research, and we use this as an opportunity to better understood subjectivity holistically in its designed, technological, embodied, political, and social dimensions.

\section{Theory Background: Sex and the Subject}

Studies of sexuality in HCI have increased since 2005, albeit sometimes in the face of resistance, which, along with dominant social norms, often wants to bracket sexuality aside irrelevant to computing, usability, and software design, except for very narrowly construed sexual technologies. But sexuality researchers in health sciences [18], sociology $[6,33,38]$, philosophy $[4,30,36]$, and the fine arts [45] offer a different point of view, one in which sexuality is not compartmentalized but rather is a basic aspect of our social life, body knowledge, and body habits. Attention to sexuality allows us to recuperate "a range of often discounted or forgotten social actors, movements, and landscapes" [15]. Our research program leverages two related ideas from this literature and explore their applicability to HCI: sexual sociability and sexual subjectivity.

Sexual sociability. Sexuality is not merely a private, but it also has an outward-turning dimension. Yet, physical pleasures are commonly assumed to be private and even antisocial. Philosopher Richard Shusterman challenges this view: "Most pleasure," he writes, "does not have the character of a specific, narrowly localized body feeling (unlike a toothache or stubbed toe). The pleasure of playing tennis cannot be identified in one's running feet, beating heart, or swing of the racket hand" [36, p.41]. Shusterman adds that "Feeling bien dans sa peau can make us more comfortably open in dealing with others" [36, p. 41]. Shusterman tightly couples physical pleasure and social competence as inseparable aspects of human body practices, and he concludes that we should cultivate, rather than repress, our capacity to experience socio-physical pleasure. This contrasts with traditional morality, in which sexual pleasures are seen as selfish and antisocial, exemplified by the myth, frequently critiqued by sex educators, that vibrators are fine for when one is alone, but not when one is in a relationship [34]. On the sociability of sexuality, psychotherapist Horrocks writes,

I construct my sexual identity not simply to obtain pleasure or love, but also to communicate who I am.... But I do not exist simply as an individual: the reason I am able to use sexuality in this complex manner is because I take part in a socialized sexual system" $[18$, p.191]

This social view of sex is mainstream in the scholarly community. It stresses that characteristics deemed "natural" about sex are in fact historically contingent and hegemonic [33]. The scholarly view has deep ethical implications:

[In] erotic life, we experience our bodies as the locus of the communication between us, and the site of our answerability to each other's perspective.... Sexuality is not 'animal,' and it is not 'amoral.' It is ... the originary ma- trix of interpersonal humanity and responsibility.... Erotic experience is experiencing the other as a person in and through experiencing oneself as a person. The epiphany of the other is the foundation of ethics [30, pp.76, 85]

Sexual subjectivity. Part of the process of socio-sexual maturity is acquiring skills of sexual perception. Sexual perception is skilled, because it must be learned, and it is mediated by our learning of related conceptual vocabularies [39]. For example, a discriminating palette for tasting wine requires not just tasting many different wines but also developing a conceptual vocabulary to name the distinctions that one learns to perceive (e.g., notes of oak, chalkiness, cherry; the mouthfeel, the finish). For Shusterman, sensory pleasure, aesthetic appreciation, and the formation of the self are all contingent on one's skill with one's body. We develop our body skills through training, understood as "actually engaging in programs of disciplined, reflective, corporeal practice aimed at somatic self-improvement" [37], including diets, exercise programs, and erotic arts. From Cosmo to The Joy of Sex, there is plenty of evidence that millions cultivate their sexual abilities.

Sexuality research helps us understand the interrelations among a complex set of tactual and social skills, body-body interactions, and body habits. $\mathrm{HCI}, \mathrm{CSCW}$, and ubiquitous computing research is already taking up such themes. To them we add that the embodied subject of interaction is gendered and sexual all the time, not just in the bedroom. It is only through such a formulation that we can begin to hear the voices of sexual subjects: "Those who have been marginalized, oppressed and pathologized begin to speak, begin to make their own demands, begin to describe their own lives, not in a spirit of scientific objectivity, but with passion, indignation, and exhalation" [18, p.187].

\section{Critical-Empirical Methodology}

For this study, we deployed both a critical analysis of sex toys and an empirical investigation of how different people react to them, partly in hopes of better understanding how these two planes of meaning related to one another, and specifically to understand how sexual subjectivities are projected by, and how they contribute to an understanding of, these toys.

Critical analysis. We offer an expert analysis of five of the toys used in the empirical portion of the study, three recognized as in the "designerly" paradigm and two from the earlier paradigm. From that analysis we produce an interpretation that helps us understand the ways that this new generation of sex toys inscribed within its toys a new (to sex toys, if not to discourse) sexual subjectivity. We use critique in the same ways it is used in the humanities, i.e., as an interpretative activity that seeks to accomplish some combination of the following: to provide a value judgment supported with reasons and evidence and to help a particular audience or public appreciate (dis)value in works of the cultural domain [9]; to reveal values and assumptions inscribed 
in works and subject them to interrogation [19]; to account for a work's most general organization and the ways that it "presents its subject matter as a focus for thought and attention" [13]. We refined this general activity to generate a set of critical prompts (summarized below), by leveraging the sexuality and subjectivity theories introduced above.

Empirical analysis. This portion of the study was labbased, in which subjects interacted with 15 different sex toys chosen, in consultation with an AASECT-certified sex educator, to represent the range of toys available, when the toys were purchased. Subjects participated in two activities: a self-guided talk-aloud exploration of the 15 toys over the course of roughly 20-30 minutes, followed up by a semistructured interview lasting 15-30 minutes. 17 study sessions were conducted with a total of 25 subjects in 9 individual sessions and 8 done in pairs, at their preference. The subject population consists of 9 male and 16 female, 22 to 33 years of age. 11 of the subjects identify themselves as heterosexual, 10 as homosexual, and 3 as queer/other, and 22 out of the 25 total subjects have prior experience with sex toys. Sessions were video-recorded with subjects' permission; afterwards, the audio from the video sessions was transcribed, and videos were used to annotate the transcriptions to clarify what was going on (e.g., which toy a participant was talking about when not obvious from the audio).

We acknowledge that lab-based interactions with 15 sex toys do not provide the same insight that in-the-wild-based interactions would. Because we obviously could not observe and interview participants during sex with each of the toys, we pursued this as a practical alternative. That said, given the expansive view of sexuality that we have just summarized-one that comprises much more than actual sexual acts and sees it instead as a basis for sociality and perception - we also believed that participants would not "turn off" their sexualities in the lab. That many of them brought their sexual partners, used language of sexual attraction/repulsion during the study, and linked their perceptions of these toys with prior experiences - all provide evidence that this is true. Moreover, the Kinsey Institute-one of the most renowned sexuality research labs in the worldconducts most of its studies in labs, for the same reasons. So while we do not provide data concerning reports of sexual acts with these toys, we do have reason to believe that our subjects engaged these toys as sexual subjects.

\section{THE CRITICAL ANALYSIS}

Our critical goal in this project is to offer an interpretation about how designs propose relationships between technology and the body-as-subject in sexually specific waysorganized around a sexual subjectivity. To interpret the designs on these terms, we began our analyses of each toy with three orienting questions: How might one characterize this as an object? What are the product features, semantics, functions; what does this design claim as pleasure and what does it ask users to give up; in what ways is it precise? How does the product design subjects? What agencies are

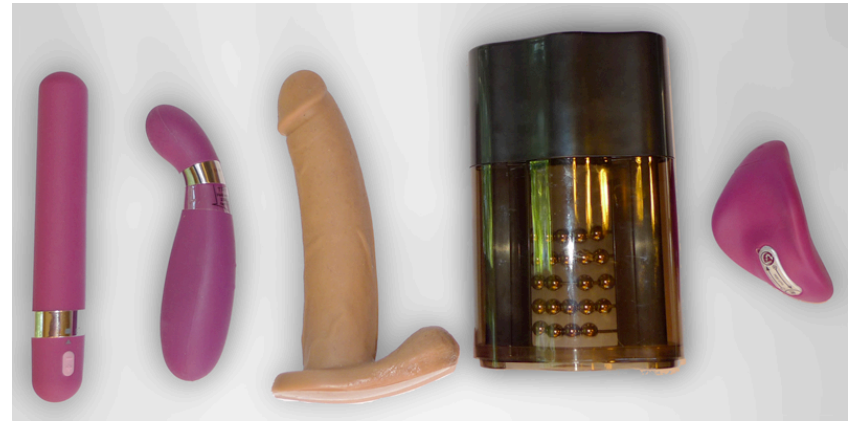

Figure 1. The five toys that were critiqued

granted or constrained; how do toys assert a relationship to the human body; what demands on perception does the toy make; what subject positions are implied? What sociocultural contingencies are expressed as norms in these toys? What would likely happen if a friend or parent discovered it; in what ways does the toy reflect, reify, or resist attitudes toward sex and issues of sexual social justice; in what ways are social relationships inscribed?

The five toys we analyzed (Fig. 1) are from left to right, the OhMiBod Freestyle, a wireless vibrator that converts MP3 audio into vibration patterns; the Jimmyjane Form 6, a jelly bean-shaped vibrator; the VixSkin Johnny, a non-vibrating dildo that simulates in detail a penis; the Maximus Power Stoker Viper, a vibrating penis sleeve; and Nomi Tang's Better Than Chocolate, a clitoral vibrator with a touchsensitive UI. Following industry experts, we divide these toys into two groups. Freestyle, Form 6, and Better Than Chocolate all represent the "designerly" turn in sex toys, which brought about the dramatic change in the industry. Johnny and Maximus represent the earlier era. They range from USD \$90-\$185, so all might be seen as on the highend of the mainstream commercial spectrum.

\section{Group 1: "Designerly" Sex Toys}

OhMiBod Freestyle. The Freestyle's distinctive feature is its wireless connectivity to an iPod, so that the audio signals from the iPod can be converted into vibrations: the idea is that the user masturbates with it to music. Its physical form is abstract and inorganic. Its shape is geometrically cylindrical, and it is symmetrical along its axes. At $21 \mathrm{~cm}$, it is considerably longer than the average human penis length, which is $12-13 \mathrm{~cm}$. The silver band that visually separates the handle end (i.e., the end that one holds, which also features the UI and the electrical jack) has no anatomic analogue, and it is clearly branded and contains UI icons of its own. The visual language of the Freestyle is that of a consumer electronic at least as much as it is of the penis.

The penis-like form, its size, and the iPod connectivity all suggest that OhMiBod is targeted at a solo female-solo because of the personal music player, female because of its pink color and form suitable for clitoral or vaginal massage. It literalizes cultural links between pop music and sexuality. The success of the device largely depends on the music one selects; beyond personal preferences, we noticed that music 
with a well defined beat produces a more structured vibration massage than music without. But the design also asks its users to give up something: social intimacy with a partner, because it invites its user to retreat into a private world of personal music and individual genital pleasure. By associating itself with iPods and consumer electronics, it also asserts itself as a middle class product, hip and youthful. In categorizing itself as another iPod-like device, it denies stigmas about sex and specifically masturbation.

Jimmyjane Form 6. This design is like the Freestyle in its color and consumer electronic aesthetic. But Form 6 is ambiguously shaped, not clearly resembling a body part nor obviously intended to couple with any particular body part. Its curvy asymmetrical shape connotes without denoting the organic. Form 6 is all about ambiguity, with its two motors, nearly invisible controls, lack of any obvious grip or handle, and diverse affordances. The larger end is large, heavy, and powerful enough to serve as a non-erotic massager, e.g., for the back. It also has rounded ridges running along its length, which do not in any literal sense represent penile ridges, but they add an organic look-feel and suggest that they might feel good when the product is inserted and rotated; the ridges also make it easier to hold, which is important for a device that is likely to have lubricant on it.

At USD \$185, the Form 6 is by far the most expensive of the six toys we critiqued. It is full featured and heavy, connoting product quality. Its price, weight, formal ambiguity, and pretentious name all connote luxury and taste: this toy suggests that sex is valuable enough to invest in, both financially and imaginatively. It demands of the user sufficient imagination to try it out in different places and different ways. But it also asks its user to give something up: its pampered, sensual, refined sexuality is intimate like a bubble bath, and it thereby resists the raunchy and gritty connotations of sexuality - bestial passion, getting dirty, etc.

Nomi Tang's Better Than Chocolate. Better Than Chocolate is placed over the vulva to mediate between the hand and the clitoris. Its bottom half conforms to the pubic mound, while its top half is fit for the hand. Its dramatic curves connote the body. One of the key features of the Better Than Chocolate is that rather than controlling vibration intensity or pattern through buttons, it uses a $4 \mathrm{~cm}$ touch slider: stroking the slider changes vibration. When the device is in place, the slider is located directly above the clitoris (on the top side of the device). Thus, controlling the device is used with similar gestures and in a similar place to stroking the clitoris itself. Sex expert Cory Silverberg (personal communication) describes this design technique as "kinaesthetic onomatopoeia," because its user interface mimics the physical action it augments. In this way, Better Than Chocolate introduces another reinterpretation of the organic, but through its interactive vocabulary and not just its form.

Better Than Chocolate's ergonomics are clever, but also inflexible; that is, the device won't fit well with any other part of the body, or in any other orientation than the single intended one; of all the designs, it is arguably the most striking in its visual form-it looks like a cross between a medical device and a sculpture. Its implied subject is a solo female. Better Than Chocolate constrains the user to a single (albeit very clever) use-clitoral stimulation. With its clever name and formal beauty, it would make a nice gift, again proposing that masturbation can be sophisticated and tasteful as well as immediately pleasurable. In this way, like the Freestyle, it also rejects stigmas about masturbation.

Taken as a group, several themes emerge. All three designs are tasteful and sophisticated. Though "pleasure objects" (as designer Lelo puts it), they are not explicit. They come in feminine colors, look like cosmetic products, and merely allude to their function. Their names are playful and girlie or pretentious - but not kinky or raunchy. All are made with body safe materials - and heavily marketed as such. They not only resemble consumer electronics, but they are made using their manufacturing processes [3]. They are expensive and they look expensive. Their subject is a classy and sophisticated woman who attends to her sexual needs like other body needs, say, skincare or feminine hygiene. Sex, then, is not special or hidden; it is just another aspect of the body needing care, and sexual taboos don't even seem to exist, or ever have existed, in this world.

\section{Group 2: Traditional Sex Toys}

We now turn to two more traditional designs, which propose different different sexual subjects.

VixSkin Johnny. The Johnny is spectacularly literal: it has an anatomically modeled glans, veins, circumcision scars, a wrinkly scrotum, and human skin color. Whereas the three preceding toys have a thin soft skin covering an extremely firm device, the Johnny is rigid but gives realistically to pressure. It is also an unusually large penis: $21 \mathrm{~cm}$ tall and $4 \mathrm{~cm}$ in diameter, made of medical grade materials. At USD $\$ 126$, the Johnny is not cheap, and yet it sells briskly.

Johnny's user is someone who straightforwardly wants a big penis to play with. In its formal and visual fidelity, it seems pornographic. As a dismembered body part, it can be used hand-held or with a strap-on. In its literalness, it asks users to give up any sense of mystery; it has no pretentions to be other than what it is. Its sheer size suggests that some people may view it as a sexual challenge: what is it like to be penetrated by something so big? It implies a view of sexuality that is based around anatomy, athleticism, and animal intensity. It neither denies nor seeks to undermine the stigma of sex: it embraces it as a source of heat.

Maximus Power Stroker Viper. The Maximus is a "beaded power masturbator" featuring a black, white, and gray color scheme, a symmetrical design, visibly cheap materials and construction (indeed, it caught on fire during a lab session). The opening in which the penis is to be inserted is white plastic with $5 \mathrm{~mm}$-long nubs in ordered rows and columns. The penis sleeve itself is surrounded by cables with $8 \mathrm{~mm}$ 
steel bearings on them, which massage the penis. Its mechanisms are all visible through its exterior shell. The product is inorganic in its design language: its shape, color, and materials do not reference the body. Its color scheme, material connotations (e.g., steel bearings), perfect rows and columns all suggest a mechanical aesthetic.

This toy suggests a masculine subject, from its masculine name to its color scheme and look-under-the-hood aesthetic. In calling itself a "masturbator" (as opposed to, say, "pleasure object") it is direct about what it is for. Thus, in its product form, semantics, and marketing, this toy asks its user to give up tenderness, allusiveness, and femininity. Indeed, like many machines, it favors functionality over aesthetics, and this functionality is well understood, well defined, and very clearly solved: put the penis in the hole, turn it on, masturbate, remove and clean. Sexuality seems to be an engineering problem with an engineered solution.

It is not our intention to argue that the theory of sexuality inscribed in one category of designs is intrinsically superior to that of another. But it certainly is clear that these two toys differ from the first grouping of toys. They are much more explicitly sexual, understood in the sense of genital attraction and stimulation and the pleasures immediately associated with them. Both of these products represent and indulge "base" or "raunchy" notions of sexuality.

\section{Discussion of Critiques}

Obviously, sexual subject positions are not created solely by the sex toy industry. Sociocultural norms have a lot to say about how we understand sexuality. Sex toys reify these norms in concrete and specific ways, which relate to but are also distinct from sexual norms presented in Sunday sermons, porn movies, advice columns, therapy sessions, and so on. In the west, there are many taboos surrounding our understanding of sexuality: the notion that sex is shameful and should be kept private is pervasive. Much of sexual practice, especially visible in consensual BDSM, involves exploring the sexual power of taboos - that which is forbidden becomes especially hot. Johnny and Maximus both position themselves within such a sexual subjectivity.

What becomes clear in contrast is that the new paradigm toys do not. They associate themselves with non-sexual forms of body care (and increasingly they are showing up in body care aisles of department stores, where one would never find Johnny), which they define in allusive and vaguely positive ways: "pleasure," "feeling sexy," "lifestyle." As critics, we are concerned with alienation, how products reify ideologies that alienate us from goods that are rightfully our own. As sex positive feminists, we view traditional sexual morality as having alienated us from sexual pleasures that are rightfully ours. But the politics here are complex. We welcome the new paradigm toys for their celebration of sexual pleasure, and they can be (and frequently are) read as exemplars of sex positive feminism.
But these toys can also be read as a form of denial: for they deny that their users are subject to sexual taboo, and by extension they also deny both the political imperative to resist repressive sexual ideologies (or suggest that by buying these one already is), and also, perversely, the sexual pleasures of transgressing them. Moreover, they frame their denial in a classist way, where high-class sexuality (reflected in the pricing, naming, and taste of the toys) is barely recognizable as sex, and by implication not subject to social powers that govern sex, while (by implication) low-class sexuality is raunchy sex and thereby subject to social censure. Such a reading suggests that the new paradigm sex toys can be read as regressive, reinforcing both a social class system and the social control of sexual life-just not for those who have the income to buy a Form 6. We will not try to resolve the progressive vs. regressive readings of these toys here, but we hope we have demonstrated that designers design subjects as well as objects, and that analysis helps us get at some of the sociopolitical consequences of that design.

\section{THE EMPIRICAL ANALYSIS}

Our empirical study was designed to help us understand sexual subjectivities: our research question was not, which toys did users like?, but rather, how did users express themselves as sexual subjects through their interactions with these toys? Linking back to the theory summarized earlier, we focus here on participants' perceptiveness, social meaning-making, and boundary-drawing.

\section{Perceptiveness}

Though study participants obviously made use of their perceptual abilities to notice the objective features of toyscolors, shape, texture - such characterizations only infrequently appear in their words. Instead, the focus of their perceptions was on the fit of toys in their lifeworlds, and objective features of the toys, rather than being seen in and of themselves, were raised in a more subjective sense. A simple example of this is how subjects articulated size.

The pocket vibrator like it could be hung, it could carry that around in a purse, you could almost carry that around in those little itty bitty like go to a bar purses. [F, 24, heterosexual, Y]

So on the side of my bed I have a little box... And it's a really nice box and I'm never like oh like I have to hide this. And oh so when I'm shopping for one I look for something that's going to fit in there. [F, 24, heterosexual, Y]

[Note: the annotation after each quote refers respectively to gender (M/F/GQ [gender queer]), age, orientation (subject's own self-description), and whether or not they have used sex toys in their personal life $(\mathrm{Y} / \mathrm{N})$.]

In both quotes, the objective quality is size, but this quality is understood in relation to other artifacts in the toy's anticipated ecology, here the containers that participants imagine themselves putting the toys in. These evaluations 
tacitly imply intentions (e.g., portability and making available) and social predispositions (e.g., the need for discretion).

Of course, like any other design, a sex toy is meant to be used, and participants' commentary on toys showed some specific ways that people anticipate use:

I don't like vibrating things because the motors make them sound like they're always screaming. I don't want to have something inside of me that's yelling unless it's yelling in pleasure. [M, 22, homosexual, $\mathrm{Y}]$

You know, if you're masturbating or having some sort of sex, do you really want to change the batteries like midstream? It just makes everything unsexy. [F, 30, lesbian, $\mathrm{Y}]$

There seems to be too much of an imitation of the penis, and the penis...doesn't do that much. So mimicking the penis is not very imaginative because it doesn't really get you what females really want or need. [M, 26, straight, Y]

A range of sexual norms are articulated in these quotes: that vibrators should not be too loud, that sexual activity is optimally experienced as a flow, and that sex toys should be imaginatively designed. Yet none of these norms is "natural" or "animal"; all of them are situated in everyday social life. Sociologist William Simon writes, "Desire is the scripting of potential futures ... drawing upon the scripting of the past desire as experienced in the contingent present. Desire, in the fullness of its implicit ambiguity, can be described as the continuing production of the self" [38, p.139]. These comments do not merely reference such scripts, as if the scripts were already whole and stored somewhere: rather, they enact and embody those scripts. So, for example, the participant is not saying that a noisy vibrator would probably turn her off were it to be introduced into a hypothetical sexual situation; instead, it is already turning her off in the moment she is saying it-even in the lab. Nor does this scripting end with the sex act:

I'd be worried about getting water and moisture in here.... that's like my number one thing is can I clean it.... I look for nice, solid, something that says it's waterproof that you can submerge the entire object in water because then I know the entire surface is able to be cleaned. [F, 28, straight, Y]

When I [have] money I will get the ones that are $\$ 100$ or so and you just toss it in the...dishwasher.... [Y] ou wash them like that, and you can use them without having to go through the steps of putting a condom on and cleaning it out. I think mine is starting to stain now, even though I use a condom...so I think yeah, that's a good criteria. [M, 22, homosexual, Y]

These comments focus on hygiene, which is a practical consideration for sex toys. But hygiene is a culturally specific activity $[35,44]$. Thus, hygiene is not an afterthought, but primary ("my number one thing"); hygiene justifies spending the money to get in the range where it is dishwashable - a culturally specific sexual hygeine practice if ever there was one.

These three sets of examples (toy size and its place in everyday life, anticipated uses, and concerns about hygiene) make clear that toys are never interpreted in terms of "just sex." This helps explain why the designerly toys - which situate themselves in relation to personal care and pleasure - are more desirable; they speak to a more holistic sociosexual subject. The one negative comment (that VixSkin is too literal) indicated that the toy is not legible beyond sex acts. We also see here that participants' imaginative exploration of the toys is temporally structured (to be carried and stored; to be used; to be cleaned up). Such characterizations are compatible with people's understandings of intimacy [28] and experience itself [24]. The toys' meanings say as much about the participants as it does about the toys themselves. Yet our participants did not use the language of critical theory; although in our critiques we discussed ideology, false pleasures, semantics, inscribed users, etc., such issues seldom explicitly came up with the users. Yet user comments that express or respond to sexual norms do bridge the two discourses, as we see in the following sections.

\section{Social Meaning-Making}

The theory of self as an outward-facing sexual subject outlined earlier this paper emphasizes the role of intersubjective experience as an input to and outcome of our sexualities. We saw plenty of evidence that intersubjective experience is central to how participants think about toys:

My partner and I for a really long time ... didn't use sex toys because it wasn't necessary.... It wasn't until we had been together for a while that we were like, hey, let's throw something else into the mix. [F, 30, lesbian, Y]

It's just kind of one more thing for me to offer my partner or myself... Yeah it's just kind of enhancing what I'm able to give her [F, 22, lesbian, Y]

If I'm looking for something for me and my partner, then we pick something that we're both going to like, and her tastes are a little bit different than mine, so we...compromise. [F, 30, lesbian, Y]

Sex toys here are meaningful inasmuch as they enhance or mediate their sexual partnership with another. Each speaker has a collaborative, not individual, relation to the toy. This sort of concrete interaction defines the self as a subject [27]. As [32, p.204] writes, "embodied subjects develop direction and purpose on the basis of the practical engagements they have with their surroundings and through the intentionality they develop as a result of the situatedness of embodied existence." The subject's practical engagements are not limited to those between partners; our bodies are also socially positioned. The presentation and interpretation of our bod- 
ies is restrained by external forces [7,32]. One external force is body norms, as the following quotes exemplify:

The problem with things like this is the belts are not made...for people who are fat. [GQ, 21, Lesbian, Y]

The sex toy assumes a normative weight, and when the participant falls outside of it, she feels "fat." Quotes like these help bridge to the critiques, because they so clearly point to ideological issues (here, norms of slenderness as beauty).

It's not adjustable in any way, so for a man to get full pleasure out of that, he has to be a particular size not any bigger not any smaller. [F, 28, Straight, Y]

Here again hegemonic norms are foregrounded. Penis size is meaningful, frequently linked to notions of masculinity, self-esteem, and racism (e.g., the perceived threat or special appeal of the stereotypically well-endowed black man). Our bodies are not merely biological but are "inscribed, marked, engraved by social pressures external to them" [17], and our subjects fluently understood such inscriptions.

Shame, implied in both of the size quotes above, is an intersubjective emotion, defined as the reaction when one sees oneself through the eyes of another in a negative way [23]. In addition to being ashamed of body properties, people can also be ashamed of its needs or pleasures:

I think that a lot of my friends and I would much more go for something smaller; something more compact something that you could hide. [F, 24, heterosexual, $\mathrm{Y}]$

I recently found out my friends would find these in their parents' rooms, their mothers' rooms. The divorced mothers, and I think everyone has that dirty little secret. [M, 22, homosexual, Y]

the cat actually found this in my sister's room. Yeah, she had gone away to college and like the cat was playing with it for a good month or so and my mom came home and was like, 'What is this?'... If I knew what I know now back then, I would have not thought it was funny but disgusting. [M, 22, homosexual, Y]

These quotes suggest three ways vibrators and masturbation are social: by involving a partner, inscribing social norms (and provoking personal reactions), and causing embarrassment/amusement when discovered. Social structuresfrom body ideals to racism - are part of the toy, and so the toys not only bear the capacity for erotic arousal and intimate creativity, but also pride/shame, disgust, indignation, and hilarity. Moreover, none of these perceptions or reactions are mutually incompatible; the same person can be subjected to and become subjects of any or all of them. An analytic understanding of such a complex response benefits from a conceptual vocabulary that can account for the copresence of diverse selves (qua subjects) as well as the complex enactments and performances that they occasion in different social situations. In such a view, it becomes clear why the more designerly toys, with their more nuanced se- mantics, provide more room for expressive agency (e.g., most people would presumably rather be discovered with a Form 6 than a VixSkin Johnny).

\section{Boundary-Drawing}

We also wanted to explore the language of acceptance or rejection of sex toys to understand what they reveal about the self and its boundaries as a sexual subject. We begin with several rejections of sex toys:

it's lime green and purple so like I'm already putting something unnatural inside my body. [F, 24, heterosexual; $\mathrm{Y}]$

I don't know if I like the size of it, and it's really hard also so I don't know if I would enjoy putting it in any holes because it might end up hurting me. [M, 22, homosexual, $\mathrm{Y}]$

She hates this material. She says it like absorbs bacteria [...], and over time it will discolor. [F, 28, straight, Y]

In each of these quotes, the relationship between the toy and the body is extremely intimate, as if the toy is a candidate to become a part of the body. Theorist Julia Kristeva proposed the concept of the abject to refer to objects in the world that challenge the borders between our bodies and the outside world: body excretions, blood, sweat, corpses, vomit, etc. [21]. Our repulsion to the abject is protective mechanism, a way of reinforcing the boundaries between self and outside when those borders are threatened. As Body theorist Blackman writes, the abject "demarcates a number of key boundaries, such as the inside and outside, the natural and the cultural, and the mind and the body.... [The body] is engendered or brought into being through two key concepts: individuation and separation." [6]

It is interesting to see that dislike was often specifically expressed as a threat, and rejection in terms of self-protection; sex toy likes and dislikes are often far stronger than mere preference statements, e.g., for flavors of ice cream. Our application of the abject also suggests specifically where participants perceive their own borders between what could be accepted into the self versus those that could not. In the above quotes, the unnatural, the physically large, and the discolored are all offered as boundaries. Yet as Kristeva's theory suggests, boundaries are movable. The same physically large toy that is intimidating to one is an object of curiosity or even a sexual challenge to another. The following quotes all explore boundary reactions, in which some aspect of the toy is threatening, but rather than rejecting it, the participant seeks ways to accommodate it:

But it seems like you would have to really lubricate well just because it like, it kind of like pulls. The texture of it kind of pulls so you'd have to definitely makes sure that you use lots of lube so there's no like pulling or tearing. [F, 22, lesbian, Y] 
this one seems like it would be a little too much because I think like too much vibration can kind of just be numbing [M, 20, homosexual, Y]

So if it's any bigger than that then I probably wouldn't want it at least not for penetration purposes. [F, 23, heteroflexible, $\mathrm{Y}]$

Size, texture, and vibration are all qualities that in some measure are acceptable and in other measures are rejected. Along the borders, then, toys perceived as challenging (as opposed to outright threatening) can be managed, e.g., with more lubricant or by changing its use. A possible outcome of management efforts is an increasingly inclusive and more specific drawing of the boundaries, which appear to reflect a certain amount of self-awareness:

I would rather have a lot, a larger range of vibrations rather than a larger range of pulsing. [F, 30, lesbian, $\mathrm{Y}]$

For vaginal stimulation it's not really a big deal; but for clitoral stimulation I have to have a big range...just so I can have a good variation $[\mathrm{F}, 23$, heteroflexible, $\mathrm{Y}]$

These are not "natural" embodied reactions but rather learned and practiced ones. Each speaker has a developed sensibility regarding the nature of vibration and its tactual effects on her body. That the toy challenges boundariesnot only physically as body penetration, but somatically as an extended body part-helps explain why sex toys are greeted with such extreme reactions-desire, repulsionand giving rise to the sober skill of managing the toy's power in one's own bodily ecosystem.

\section{Discussion of Empirical Findings}

The critical perspective was strong at analyzing links between design choices to sociocultural issues, e.g., how toys embody and replicate class norms and ideologies, how toys participate in activist challenges to traditional morality, and how sexual experiences can be offered up as/in products. The empirical findings also provided linkages between specific design choices and experiences, but in more concrete terms. They revealed how design choices exposed (or pushed) the boundaries of participant sexuality: what was desirable, what was possible under what conditions, and what must be rejected outright both from a physical perspective (e.g., too big, wrong color) and from a social perspective (e.g., too shameful to acknowledge, reifies regressive body ideals). The findings also reveal how sexuality relates to other parts of life, e.g., storage and hygiene. The emphatic reactions emphasized how much these toys are literally incorporated, taken into the body, and how powerful, for better and for worse, that move is. The body is changed, both to oneself and to the social world. This change is a powerful experience to the self; the discovery that one's partner (or mother!) has been subjected to such change is socially significant; as is the realization that one's body is ineligible for such change (e.g., one is "too fat" or "too small").

\section{SUBJECTIVITIES OF INFORMATION}

Subjectivity theory, developed in the context of postmodernism, might come across as radical, proposing a "fragmented self" that lacks unity or coherence, in stark contrast to our intuitive sense of ourselves as unified wholes. On the other hand, the idea that our sense of self is shaped by our participation in social structures (parent-child, teacherstudent, partner-partner), and that we have some agency in how we embody and perform such roles, seems intuitive. We argue for subjectivity theory in HCI not in a metaphysical sense, as if to assert that "subjectivities of information" somehow corresponds better to reality as the "hidden truth" about how we "really are." Rather, we argue that this formulation has pragmatic benefits for research and design.

The strength of this theory is its ability to account for the mutability of selfhood, as it negotiates the boundaries of internal experience and intention and our (designed) environments and social reality. If we view the self as unified and even fixed, it limits design to "supporting" and "augmenting" existing capabilities (and much of HCI literature uses these terms). If we can understand the mechanisms by which selves change - as embodied social beings situated in sociotechnical environments and practices-then we can look beyond supporting and augmenting towards the hope and the ideal of social change. From environmental sustainability to social media, and from participatory design to action research and feminist $\mathrm{HCI}$, the field has been aspiring to contribute to social change. In doing so, it has already begun to explore many humanistic concepts and methodologies. For this reason, we believe that many in the field are already embracing, if tacitly, some version of subjectivities of information, from Turkle's Life on the Screen to research on the "quantified self." Our hope here is to offer an argument, a set of concepts, an example, as a provocation that helps frame and consolidate these developments.

Near the beginning of this essay, we argued that this theory provides a tight analytic coupling between specific design decisions and particular socio-subjective experiences; a vocabulary to reason about the ways that we can design subjects as well as interfaces, products, and services (without denying human agency enacted in subjectivities); and a means to get at design aimed at cultivating and transforming, rather than merely supporting or extending, human agency. We conclude by returning to these three claims.

\section{Linking Design Choices with User Experiences}

Aristotle in his Poetics exemplifies an analysis that links formal features of literary genres (e.g., tragedy and epic) to subjective experiences and social significances, e.g., how the form of a tragic reversal in a tragedy causes feelings of pity and fear in the audience, which then purge them of their own emotions, reestablishing their rationality. Our critical analysis likewise seeks to understand how the product semantics of certain contemporary sex toys cohere with certain particular kinds of experiences, themselves situated in certain social meanings. More specifically, we followed 
experts in distinguishing between two categories of sex toys-earlier adult novelty products vs. more recent "designerly" lifestyle accessories - to interpret how the designs project subject positions as part of their meaning.

In our empirical study, we gained a sense of individuals perceive, interpret, and tell stories about sex toys. A common statement involved a participant pointing to something specific about the design (a shape, color, texture) and then relating it to experience (how it would feel, its implications for hygiene, how one might hide it). Such statements can add up to a poetics in their own right. Thus, even though we view subject positions as inscribed in objects and available to researchers analytically through interpretation, and we view subjectivities as part of human experiences and available to research via empirical studies, they need not be incommensurate. To the extents that these two modes of analysis overlap increases confidence in the findings.

\section{Designing Subjects as Well as Interfaces}

Both our critical and empirical studies pointed to two different sexual subjectivities. Earlier sex toys propose a raunchy and transgressive sexual subject, who finds pleasure in genital attraction/sensation in precisely the ways that are taboo in traditional morality. The toys construct this subjectivity through their blunt visual and functional appeal to sex acts, including literal replication of anatomy, pornographic packaging, overt problem-solving functionalism, as well as more subtle features, such as vibrator controls that face away from a woman (i.e., so her partner can control them).

As sex positive feminism gained momentum over the decades, however, an alternative sexual subject was offered: a body-conscious woman, who takes care of her physical needs with taste, discrimination, and consumer choice. The designerly sex toys speak to this subject, in their forms, materials, and marketing. Such features include more abstract shapes that connote but do not denote sexual organs, feminine color palettes instead of skin tones (especially bright pinks and purples), formal allusions to cosmetics (e.g., the silver band on the Freestyle), emphasis on health (e.g., body safe materials), and euphemistic marketing.

It is important to stress that any individual can choose between these subjectivities, embracing one, the other, both, or neither-and that this choice can be made again and again, changing over time. One can be in the mood for raunchy and transgressive sex one day, and be in the mood for something more sensual and synesthetic then next. It is also possible to start predominantly in one place and then to change one's tastes, or form new desires, over time. Designs - and the images of sexual life inscribed within them-can help effect such changes.

\section{Cultivating and Transforming Human Agency}

Dewey frequently reminds us in his writings that humans are organisms, that we adapt to our environments. As ubiquitous computing, Internet of Things, and wearable comput- ing becomes a reality, we are constructing new environments and human organisms will adapt. Part of this means the acquisition of new skills of perception and a precise conceptual vocabulary to grasp and to express them: no one is born with a capacity to explicate a sex toy feature's physical, sexual, romantic, social, and ideological consequences (e.g., reification of body weight norms and penis size). Part of it also means researchers and designers improving their own conceptual grasp: for example, the way that our subjects perceived and interpreted the significance of toys as (prospectively) part of their bodies would seem to raise potentially generative concepts about wearable technologies.

Our study of sex toys, which comprises expert interview studies, critical analysis of toys, and empirical studies of sexual experiences, has helped us grasp not only the emerging paradigm of designerly sex toys compared to what came before it in design historical terms, but more importantly to understand its tremendous range of significance: from intensely personal experiences to forms of public activism, literal orgasms to public shame, product design history to third wave feminism, and law enforcement to pop music. Each of these is an opening to forms of agency: to try out a new sexual experience, to become active in sexual politics, to jump into sex toy design, to become more sex educated and/or an educator. It is not our position that design alone causes such transformations, but it is our position that design can contribute meaningfully to such transformations, and subjectivity theory, and a critical-empirical research methodology, can help us understand them better. Because designers in HCI are hoping to contribute such transformations, we believe a reconceptualization of the user as a subjectivity of information will be salutary.

\section{ACKNOWLEDGMENTS}

We thank Cory Silverberg, Gopinaath Kannabiran, and Katie Quehl for their contributions to this study. We thank our peers in the Intel Science and Technology Center for Social Computing for their contributions to this research, and to Intel for supporting the research. We also thank our reviewers for their tough questions.

\section{REFERENCES}

1. Bannon, L., and Bødker, S. (1991). Beyond the interface: Encountering artifacts in use. In Designing Interaction: Psychology at the Human-Computer Interface. Carooll, J. (eds.). Cambridge UP, 227-253.

2. Bardzell, J. (2011) Interaction criticism: an introduction to the practice. Interacting with computers 23(6): 604621.

3. Bardzell, J., and Bardzell, S. (2011). "Pleasure is your birthright": Digitally enabled designer sex toys as a case of third-wave HCI. Proc. of CHI'11.

4. Bell, S. (2010) Fast Feminism. Autonomedia.

5. Bertselsen, O. \& Pold, S. (2004). Criticism as an ap- 
proach to interface aesthetics. Proc. of NordiCHI'04, ACM Press, 23-32.

6. Blackman, L. (2008). The Body. Berg.

7. Butler, J. (1993). Bodies that matter: On the discursive limits of sex. Routledge.

8. Card, S., Moran, T., Newell, A., 1983. The Psychology of Human-Computer Interaction. Lawrence Erlbaum Associates Publishers.

9. Carroll, N. (2009). On criticism. Routledge.

10. Cockton, G. (2008). Revisiting usability's three key principles. CHI2008 EA. 2473-2484.

11. Cooper, G., and Bowers, J. (1995). Representing the user: Notes on the disciplinary rhetoric of humancomputer interaction. In Thomas, P. (ed.). The social and interactional dimensions of human-computer interfaces. Cambridge UP.

12. Dourish et al. (2012). Research Themes: Intel Science and Technology Center for Social Computing. http://socialcomputing.uci.edu/content/research-themes

13. Eldridge, R. (2003). An introduction to the philosophy of art. Cambridge UP.

14. Goodman, E. and Vertesi, J. (2012). Designing for X? Distribution choices and ethical design. CHI'12 EA. ACM Press.

15. Gordo López, Á., and Cleminson, R. (2004). Technosexual Landscapes: changing relations between technology and sexuality. Free Association Books.

16. Gould, J. \& Lewis, C. (1985) Designing for usability: Key principles and what designers think. Communications of the ACM 28(3), ACM Press, 300-11.

17. Grosz, E. (1994). Volatile bodies: Toward a corporeal feminism. Indiana University Press.

18. Horrocks, R. (1997). An introduction to the study of sexuality. Macmillan Press, Ltd.

19. How, A. (2003). Critical Theory. Palgrave Macmillan

20. Irani, L., Vertesi, J., Dourish, P., Philip, K., and Grinter, B. (2010). Postcolonial computing: A lens on design and development. Proc. of CHI'10. ACM.

21. Kristeva, J. (1980). Powers of horror: An essay on abjection. Columbia UP.

22. Kuutti, K. (2001). Hunting for the lost user: From sources of errors to active actors - and beyond. Cultural Usability Seminar, Media Lab, University of Art and Design Helsinki, 24.4.

23. Laine, T. (2007). Shame and desire: Emotion, intersubjectivity, cinema. Peter Lang.

24. McCarthy, J., and Wright, P. (2004). Technology as experience. MIT Press.

25. Nielsen, J. (1993). Usability Engineering. Morgan Kaufmann.
26. Norman, D., 2002. The Design of Everyday Things. Basic Books, New York.

27. Nussbaum, M. (1999). Sex and social justice. Oxford UP.

28. Pace, T., Bardzell, S., and Bardzell, J. (2010). The rogue in the lovely black dress: Intimacy in World of Warcraft. Proc. of CHI'10. ACM.

29. Radway, J. (1984). Reading the romance: Women, patriarchy, and popular literature. The University of North Carolina Press.

30. Russon, J. (2009). Bearing witness to epiphany: Persons, things, and the nature of erotic life. SUNY Press.

31. Satchell, C., and Dourish, P. (2009). Beyond the user: Use and non-use in HCI. Proc of $\mathrm{OzCHI}^{\prime}$ 09. 9-16.

32. Schilling, C. (1993). The body and social theory. Sage.

33. Seidman, S. (2003). The social construction of sexuality. W.W. Norton \& Company.

34. Semans, A. (2004). The many joys of sex toys: The ultimate how-to handbook for couples and singles. Broadway Books.

35. Shove, E. (2003). Comfort, cleanliness, and convenience: The social organization of normality. Berg.

36. Shusterman, R. (2008). Body consciousness: A philosophy of mindfulness and somaethestics. Cambridge UP.

37. Shusterman, R. (2011): Somaesthetics. In: Soegaard, M. and Dam, R.F. (eds.). Encyclopedia of HumanComputer Interaction. Aarhus, Denmark: The Interaction Design Foundation.

38. Simon, W. (1996). Postmodern sexualities. Routledge.

39. Sonneveld, M., and Schifferstein, H. (2008). The tactual experience of objects. In Schifferstein, H., and Hekkert, P. (eds.). Product experience. Elsevier.

40. Suchman, L., 1987. Plans and Situated Actions: The Problem of Human-Machine Communication. Cambridge University Press, Cambridge, UK.

41. Sutcliffe, A. (2010) Designing for user engagement: Aesthetic and attractive user interfaces, Synthesis Lectures on Human-Centered Informatics. Morgan \& Claypool Publishers.

42. Taylor, A. (2011). Out there. Proc. of CHI'11. ACM.

43. Thornham, S. (1997). Passionate detachments: An introduction to feminist film theory. Arnold.

44. Vigarello, G. (1998). Concepts of cleanliness: Changing attitudes in France since the Middle Ages. Cambridge UP

45. Watson, G. (2008). Art \& Sex. I.B. Tauris.

46. Winograd, T., Flores, F., 1986. Understanding Computers and Cognition: A New Foundation for Design. Ablex Corporation, Norwood, NJ. 